seen in stroke but with hypometabolism possibly representing a phenomenon of diaschisis. Serial FDG-PET examinations showed markedly increased activity in the basal ganglia as compared with that in the cortex when extrapyramidal features were prominent, which normalised after improvement of this movement disorder ${ }^{4}$. In the setting of paraneoplastic neurological syndrome, FDG-PET imaging can be of value from the following standpoints: [1] detection of the occult malignant focus and [2] objective assessment of the presence and extent of the functional abnormality in the brain and correlation of the imaging findings with the clinical features and disease activity ${ }^{5}$. The literature describing the central nervous system findings with PET in paraneoplastic neurological syndromes are primarily restricted to paraneoplastic limbic encephalitis. FDG-PET usually shows hypermetabolism in one or both temporal lobes, and the magnetic resonance imaging (MRI) findings correlate with the FDG-PET scan results in only a fraction of cases. FDG-PET images can provide additional clinical information which is of great value in further patient management.

In conclusions, the FDG-PET more often than the MRI revealed abnormalities in the brainstem, cerebral cortex or cerebellum, some of them clinically silent.

FDG-PET might be useful in the evaluation of patients suspected for NMDA receptor encephalitis, but studies to asses the utility for prognosis and treatment planning are necessary.

\section{REFERENCES}

1. Irani SR, Bera K, Waters P, et al. N-methyl-D-aspartate antibody encephalitis: temporal progression of clinical and paraclinical observations in a predominantly non-paraneoplastic disorder of both sexes. Brain 2010;133: 1655-1667.

2. Dalmau J, Tüzün E, Wu H, et al. Paraneoplastic Anti-N-methyl-D-aspartate receptor encephalitis associated with ovarian teratoma. Ann Neurol 2007;61:25-36

3. Vitaliani R, Mason W, Ances B, Zwerdling T, Jiang Z, Dalmau J. Paraneoplatic encephalitis, psychiatric symptoms, and hypoventilation in ovarian teratoma. Ann Neurol 2005;58:594-604.

4. Maeder-Ingvar M, Prior JO, Irani SR, Rey V, Vincent A, Rossetti AO. FDGPET hyperactivity in basal ganglia correlating with clinical course in antiNMDA-R antibodies encephalitis. J Neurol Neurosurg Psychiatry 2011;82: 235-236.

5. Basu S, Alavi A. Role of FDG-PET in the clinical management of paraneoplastic neurological syndrome: detection of the underlying malignancy and the brain PET-MRI correlates. Mol Imaging Biol 2008;10:131-137.

\section{EMISSÃO DE POSITRON FLUORODEOXYGLUCOSE NA ENCEFALITIDE DE} RECEPTOR ANTI-NMDA

Medical Doctor, Neurologist, Department of Neurology, Hospital Virgen de la Salud, Toledo, Spain.

Correspondence: Pedro Enrique Jiménez Caballero - Calle Dionisio Acedo no 9 / Portal 7, 4-1 - 10001 Cáceres - Spain. E-mail: pjimenez1010j@yahoo.es

Received 10 January 2011. Received in final form 7 February 2011. Accepted 14 February 2011.

\title{
Myasthenia gravis complicated with cryptococcal meningitis after thymectomy and long-term immunosuppressive therapy
}

\author{
Paulo J. Lorenzoni, Rosana H. Scola, Cláudia S.K. Kay, Sérgio M. Almeida, \\ Marisol D. Muro, Ismael P. Búrigo, Hipólito Carraro Jr, Lineu C. Werneck
}

Myasthenia gravis (MG) is an immune-mediated disease that compromises the postsynaptic membrane of the neuromuscular junction ${ }^{1,2}$. Common treatments for MG include immunosuppressive drugs and thymectomy ${ }^{1,2}$.

Cryptococcal meningitis (CM) is caused by the encapsulated yeast Cryptococcus neoformans, which is most notably known as an opportunistic infection in patients with human immunodeficiency virus (HIV) ${ }^{3}$. Development of CM is extremely rare in the HIV-negative population and is usually seen in the setting of diseases involving marked cell immunodeficiency ${ }^{3}$.

\section{CASE REPORT}

This report describes a 42-year-old woman who presented with intermittent diplopia, limited ocular movements, progressive eyelids ptosis and proximal limb weakness, which increased during periods of activity and decreased after periods of rest. The investigation yielded the following results: positive anti-acetylcholine receptor antibody test $(1.09 \mathrm{nmol} / \mathrm{l}$; normal $<0.20 \mathrm{nmol} / \mathrm{l})$; recordings of compound muscle action potential with an abnormal decrement of greater than 10\% during repetitive nerve stimulation; symptom improvement after 


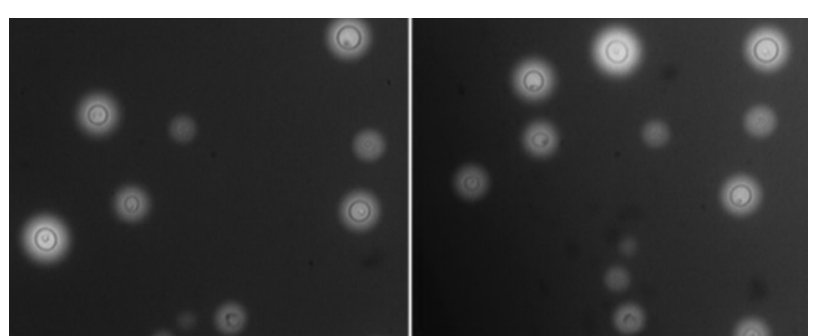

Figure. Cerebrospinal fluid analysis showed encapsulated yeast Cryptococcus neoformans (Nankin ink stain, 1000×).

pyridostigmine treatment; and normal chest computed tomography scan. A diagnosis of generalized MG was made and the patient was prescribed pyridostigmine and prednisone. No remission of the disease was observed after one year of treatment; therefore, azathioprine was added to the treatment regimen. The patient also underwent thymectomy and subsequently went into remission. Pathological investigation revealed that the thymus was hyperplastic, but without signs of neoplasia.

At 46 years of age, the patient was still using pyridostigmine and azathioprine, but for one month had been experiencing progressive headaches associated with nausea, vomiting and weakness, with a temperature of $37.9^{\circ} \mathrm{C}$. A neurological examination showed mild limitation of ocular movements, bilateral eyelid ptosis, neck stiffness, Kernig's sign, Brudzinski's sign and mild paresis of both arms and legs (MRC grade 4). A brain computed tomography scan was normal. Lumbar puncture showed an increased opening pressure of $320 \mathrm{mmH}_{2} \mathrm{O}$, and lumbar cerebrospinal fluid analysis revealed 525 white blood cells $/ \mathrm{mm}^{3}$ (6\% monocytes, $9 \%$ polymorphonuclear cells, and $85 \%$ lymphocytes), total protein of $67.4 \mathrm{mg} / \mathrm{dl}$ and glucose of $7 \mathrm{mg} / \mathrm{dl}$. Encapsulated yeast suggestive of Cryptococcus sp could be viewed directly (Figure). The latex agglutination method (titer of 1:10,000) was positive for cryptococcal antigen. Cerebrospinal fluid culture growth showed encapsulated yeast compatible with Cryptococcus neoformans. Serum cryptococcal antigen was detectable (titer of 1:10,000). HIV ELISA tests were negative. The $\mathrm{CD}^{+}$and $\mathrm{CD} 8^{+}$cell counts were 342 and 192 cells/ $\mathrm{mm}^{3}$, respectively, and glucose was elevated $(160 \mathrm{mg} / \mathrm{dl})$.

The patient was treated with amphotericin B, which resulted in a marked and prompt improvement of her symptoms and cerebrospinal fluid analysis.

\section{DISCUSSION}

The majority of HIV-negative patients who present with CM are apparently healthy, but predisposing factors can be identified in about a third of the cases ${ }^{3}$. Our patient had diabetes mellitus, and was on long-term immunosuppressive treatment, which could have predisposed her towards CM.

Although not surprising in an MG patient under immunosuppression, this is only the third case report of MG complicated with $\mathrm{CM}^{4,5}$. In the two other cases reported thus far, $\mathrm{CM}$ followed neoplasms of the thymus (thymic carcinoma), thus suggesting that thymic carcinoma might be a prerequisite for the development of $\mathrm{CM}$ in patients with $\mathrm{MG}^{4,5}$. However, although our patient underwent thymectomy, her thymus only showed hyperplasia, and no signs of neoplasm were found. The results from this study support the view that thymic neoplasia may not be the only prerequisite for the development of $\mathrm{CM}$. Thymic dysfunction, caused by neoplasia or the lack of a functional thymus through thymectomy, could itself be a precipitating factor for the development of CM.

\section{REFERENCES}

1. Werneck LC, Cunha FMB, Scola RH. Myasthenia gravis: a retrospective study comparing thymectomy to conservative treatment. Acta Neuro Scand 2000;101:41-46

2. Hohlfeld R, Michels M, Heininger K, Besinger U, Toyka KV. Azathioprine toxicity during long-term immunosuppression of generalized myasthenia gravis. Neurology 1988;38:258-261.

3. Lui G, Lee N, Ip M, et al. Cryptococcosis in apparently immunocompetent patients. Q J Med 2006;99:143-151.

4. Rowland LP, Griffiths CO, Kabat EA. Myasthenia gravis, thymoma and cryptococcal meningitis. N Engl J Med 1965:273:620-627.

5. Schmidt S, Padberg F. Late onset immunodeficiency in a patient with recurrent thymic carcinoma and myasthenia gravis. J Neurol Sci 1998; 157:201-205.

MIASTENIA GRAVIS COMPLICADA POR MENINGITE CRIPTOCCÓCICA APÓS TIMECTOMIA E TRATAMENTO PROLONGADO COM IMUNOSSUPRESSOR

Neurology Division, Internal Medicine Department, Hospital de Clínicas, Universidade Federal do Paraná (UFPR), Curitiba PR, Brazil.

Correspondence: Rosana Herminia Scola - Serviço de Doenças Neuromusculares / Hospital de Clínicas da UFPR - Rua General Carneiro 181 / $3^{\circ}$ andar - 80060-900 Curitiba PR - Brazil. E-mail: scola@hc.ufpr.br

Received 30 October 2010. Received in final form 18 February 2011. Accepted 25 February 2011 